\title{
Effects of received and mobilized support on recipients' and providers' self-efficacy beliefs: A 1-year follow-up study with patients receiving radical prostatectomy and their spouses
}

\author{
Nina Knoll ${ }^{1}$, Urte Scholz ${ }^{2}$, Silke Burkert ${ }^{3}$, Jan Roigas ${ }^{3}$, and Oliver Gralla ${ }^{4}$ \\ ${ }^{1}$ Charité - Universitätsmedizin Berlin, Germany \\ ${ }^{2}$ University of Zurich, Switzerland \\ ${ }^{3}$ Charité - Universitätsmedizin Berlin, Germany \\ ${ }^{4}$ University Hospital of Cologne, Germany
}

\begin{abstract}
$F$ rom a proactive agentic perspective, social support is not just seen as a protective cushion against environmental demands. Rather, support may facilitate an individual's self-regulation by enhancing perceived self-efficacy (i.e., enabling hypothesis). In the present study, patient-reported indicators of mobilized and received spousal support as predictors of their own and their spouses' self-efficacy beliefs were investigated within 1 year following radical prostatectomy. During this time frame, postoperative sequelae such as urinary incontinence and erectile dysfunctions are still likely to interfere with couples' everyday activities. Seventy-two patients receiving radical prostatectomy and their spouses participated. Patients' and spouses' self-efficacy beliefs and patients' received and mobilized spousal support were assessed prior to and 12 months following surgery. Additional patient-reported covariates at 1 year post-surgery were degree of bother by urinary incontinence, overall sexual satisfaction, and relationship satisfaction. Results indicated that patients' received spousal support was associated with higher levels of patients' self-efficacy only cross-sectionally, but not longitudinally. Support mobilized by the patient prior to and I year after surgery, however, positively predicted spouses' levels and changes in self-efficacy. Results, thus, did not fully confirm predictions by the enabling hypothesis of social support; rather, associated aspects, such as the degree of being mobilized as a provider of support or being needed, seem to enhance agency beliefs in spouses.
\end{abstract}

\begin{abstract}
elon une perspective proactive agentique, le soutien social n'est pas seulement vu comme un tampon $\checkmark$ protecteur contre les demandes environnementales. En effet, le soutien peut plutôt faciliter l'auto-régulation d'un individu en favorisant la perception de l'auto-efficacité (i.e. hypothèse opérationnelle). La présente étude a examiné les indicateurs rapportés par les patients concernant le soutien conjugal mobilisé et reçu dans l'année suivant une prostatectomie radicale en tant que prédicteurs de leurs propres croyances d'auto-efficacité et de celles de leurs conjointes. Dans ce cadre temporel, des séquelles postopératoires telles que l'incontinence urinaire et les dysfonctions érectiles sont toujours enclines à interférer avec les activités quotidiennes du couple. Soixantedouze patients recevant une prostatectomy radicale et leurs conjointes ont participé à cette étude. Les croyances d'auto-efficacité des patients et celles de leurs conjointes ainsi que le soutien conjugal des patients reçu et mobilize a été évalué avant et 12 mois après l'opération. Les covariables rapportées par les patients un an après l'opération étaient le degré de dérangement causé par l'incontinence urinaire, la satisfaction sexuelle globale et la satisfaction. relationnelle. Les résultats ont indiqué que le soutien conjugal reçu par les patients était associé avec des niveaux plus élevés d'autoefficacité chez les patients seulement de manière transversale et non pas longitudinalement. Le soutien mobilisé par le patient avant et un an après l'opération a cependant prédit positivement les niveaux et les changements d'auto-efficacité. Ainsi, les résultats n'ont pas complètement confirmé les prédictions par l'hypothèse opérationnelle du soutien social. Plutôt, des aspects associés tels que le degré d'être mobilisé comme donneur du soutien ou le fait de se sentir utile semblent favoriser les croyances des conjointes sur l'efficacité et les consequences de leurs actions.
\end{abstract}

Correspondence should be addressed to Nina Knoll, Charité - Universitätsmedizin Berlin, Institute of Medical Psychology, Luisenstrasse 57,10117 Berlin, Germany (E-mail: nina.knoll@charite.de).

We wish to thank Friederike Haas and Thomas Stocker for research assistance. 


\begin{abstract}
$D$ esde una prespectiva proactiva utilitaria no se considera al soporte social solamente como un amotiguador protectivo en contra de las demandas del medio ambiente. El soporte social puede también facilitar una autoregulación individual a través de la mejoría en la percepción de la autoeficacia (ver hipótesis propuesta). En el presente estudio se investigaron los indicadores reportados por los pacientes respecto del soporte mobilizado y recibido por parte de la pareja como predictores de sus creencias respecto de la propia autoeficacia y de la autoeficacia de la pareja en el transcurso de un año después de una prostatectomía radical. Durante este período de tiempo es muy probable que secuelas postoperativas como incontinencia urinaria y disfunción erectil interfieran con las actividades cotidianas de las parejas. Setenta y dos pacientes que fueron sometidos a una prostatectomía radical y sus esposas tomaron parte de la investigación. En este estudio se evaluaron tanto las creencias sobre la autoeficacia de los pacientes y de sus esposas, así como el soporte social mobilizado y recibido por parte de los pacientes antes y doce meses después de la operación. Covarianzas adicionales reportadas por los pacientes un año después de la intervención quirúrgica fueron el grado de molestia generado por la incontinencia urinaria, la satisfacción sexual global y la satisfacción con la relación de pareja. Los resultados señalaron que el soporte social que los pacientes recibieron por parte de sus esposas estuvo asociado con altos niveles de autoeficacia de los pacientes en los datos transversales, más no en los datos longitudinales. Por otro lado, el soporte mobilizado por los pacientes antes de la operación y un año después de la misma se asociaban de manera positiva con los niveles y los cambios en la autoeficacia de las esposas. Estos resultados, sin embargo, no confirman de una manera absoluta las predicciones de la hipótesis de soporte social propuesta. Parece ser más bien que aspectos asociados, como el ser mobilizado como proveedor de soporte o el ser necesitado, son los que posibilitan una mejoría en las creencias de utilidad de las esposas.
\end{abstract}

From a proactive agentic perspective, social support may not just be a protective buffer against environmental demands, but a potential catalyst for the recipients' self-efficacy beliefs (Schwarzer \& Knoll, 2007). In accord with Benight and Bandura (2004), this assumption may be referred to as the enabling hypothesis of social support.

Perceived general self-efficacy is a personal resource that refers to the optimistic self-belief in one's competence to exercise control over a range of difficult tasks and to cope with adverse events (Schwarzer, 1992). Self-efficacious individuals pursue challenging goals, invest effort, and persist in the face of obstacles and challenges (e.g., Bandura, 1997).

Enabling aspects of social support may be manifold (Bandura, 1997; Benight \& Bandura, 2004). Providers of support may encourage new behaviours in recipients, thereby triggering mastery experiences. Also, social support may provide an opportunity to learn from vicarious experiences how to successfully deal with stress. Moreover, it may represent a symbolic experience (e.g., by means of verbal persuasion) in which members of the network provide verbal assurances of the support recipient's competency to deal with the problem. A fourth pathway connecting social support with self-efficacy may place the reduction of emotional or physical arousal in a mediator position. High emotional arousal is sometimes used as a source of information concerning one's own reduced competency to cope with the situation at hand. Social support may reduce stress-related arousal and thus provide another source of increased self-efficacy. Mastery experiences usually serve as the most effective source of self-efficacy.

\section{Perceived support versus received support and self-efficacy}

Although the enabling function of social support has received little attention, evidence suggests that the utilization of social resources might be beneficial for self-efficacy beliefs. However, studies reporting such positive associations have often tested effects of perceived support on self-efficacy (e.g., Cheung \& Sun, 2000; Duncan \& McAuley, 1993; Saltzman \& Holahan, 2002). Perceived support refers to the fairly stable belief that network members will come to aid in times of need. It is usually measured prospectively and reflects only to a medium degree outcomes of actual support interactions.

Received support is assessed by retrospective reports of support transactions that have been encoded as such by the recipient of help. Effects of received support on self-efficacy are even more rarely investigated. Luszczynska, Sarkar, and Knoll (2007) have examined predictors of adherence to highly active antiretroviral therapy in AIDS patients. They found effects of social support on outcomes to be mediated by perceived selfefficacy. Also, in a longitudinal study with cardiac patients, Schröder, Schwarzer, and Konertz (1998) found that received support delivered its beneficial 
effect on physical symptom experience only through perceived self-efficacy. Although this evidence indicates that support receipt is positively associated with concurrent or future levels of agency beliefs, these studies did not test associations between support and changes in self-efficacy.

\section{Different constituents of the support process predict self-efficacy?}

Support interactions may not only include the receipt of help, but also its mobilization. Aside from its usual conceptualization as a reactive coping strategy (Carver, 1997), mobilization of support can also be conceived of as a proactive utilization of external resources to exert (indirect) control over a situation, i.e., mastering demands by enlisting someone else's help (e.g., Heckhausen \& Schulz, 1993). If successful, mobilization of support, both as a precursor of received support as well as in its own right, may thus be linked with higher self-efficacy beliefs in recipients.

On the side of the potential supporters, being asked for help could serve as an indirect symbolic experience in which the providers of support receive feedback about their competence as it is perceived by the person in need. Additionally, being mobilized to provide support may also entail the acquisition of new skills to master new demands, such as during early phases of caregiving for ill family members. For example, Aneshensel, Pearlin, Mullan, Zarit, and Whitlatch (1995) reported that mastery experiences in caregiving resulted in increased self-efficacy beliefs as a caregiver over time.

\section{The study context: Convalescence following radical prostatectomy}

In the present study, couples were studied in which one partner recovered from long-term post-operative morbidities following tumour surgery, i.e., radical prostatectomy. Radical prostatectomy (RP) refers to the removal of the entire prostate gland between urethra and bladder, with bilateral resection of the seminal vesicles. The two most common post-operative morbidities following RP are urinary incontinence and erectile dysfunction. Findings indicate that both of them, although at different intensities, affect the patients' emotional well-being and physical functioning, especially within the first year following the operation (Eton \& Lepore, 2002). In addition, both may also be related to the patients' self-efficacy beliefs (e.g., Broome, 2003). For instance, in a study on early quality of life in patients with localized prostate carcinoma within 7 weeks of treatment initiation, Eton, Lepore, and Helgeson (2001) found significant cross-sectional correlations of self-efficacy beliefs with urinary and sexual functions.

Furthermore, studies investigating couples' adaptation to treatment for prostate carcinoma indicated that not only for patients, but also for spouses, treatment consequences affect well-being (Gray, Fitch, Phillips, Labreque, \& Fergus, 2000) and even physical functioning (e.g., sexuality; Shindel, Quayle, Yan, Husain, \& Naughton, 2005). As a consequence of losses in their own emotional and physical functioning, spouses too may experience changes in their self-efficacy beliefs following their partner's prostatectomy. As self-efficacy has important functions for selfregulation in the face of barriers, factors that may affect both partners' self-efficacy beliefs in the aftermath of prostatectomy should yield important information on the process of adapting to this situation.

In this study, the effects of prior and concurrent patient-reported received and mobilized spousal support on patients' own as well as their partners' self-efficacy beliefs at 1 year post-surgery were explored. Extending Benight and Bandura's enabling hypothesis of social support, we assumed that higher patient-reported received and mobilized support should be associated with higher levels and positive changes in their own selfefficacy beliefs over 1 year post-surgery. Additionally, we hypothesized that spouses' levels and changes of self-efficacy beliefs should be positively associated with patients' mobilization of spousal support. As further competing predictors, patients' degree of bother by urinary incontinence, overall satisfaction with sexuality, and relationship satisfaction at 1 year post-surgery were tested (cf. Coyne \& Smith, 1994).

\section{METHODS}

\section{Sample and design}

Seventy-seven couples agreed to participate. Questionnaires were used pre-surgery $(t 1)$ and 1 year post-surgery (t2). T1 took place upon the patients' admission to the Urology Department 1 day prior to surgery. At $\mathrm{t} 2$ questionnaires were sent via mail. Exclusion criteria were not having a partner or the partner's refusal to participate in the study and insufficient comprehension of the German language. The study was approved by an ethical committee. 
Of 77 couples, 51 provided full data $(66.2 \%)$. In 10 couples, one partner missed one assessment, in 11 couples, each partner missed one assessment. In 5 couples, one partner missed both assessments relevant for this study, but provided data at other measurement points not reported here. These 5 couples were not included in the analyses; thus, the present sample amounted to $N=72$ couples. In couples who failed to return their data fully, patients tended to report lower health-related quality of life (SF-12, Bullinger \& Kirchberger, 1998; $r=-.22, p<.07)$ and more mobilization of spousal support $(r=.26, p<.05)$. To account for the pattern of missing data, we employed multiple imputation (NORM 2.03; Schafer, 1999), including the above-reported missing-related variables in the imputation model. Multiple imputation reflects the uncertainty of missing data by introducing between-imputation variance. For the present study, results from 10 datasets were generated and integrated in a last step by means of a method proposed by Rubin (1987) to obtain overall estimates and standard errors.

Patients' mean age was 61.2 years $(S D=6.03)$, spouses' mean age was 58.1 years $(S D=7.49$ ). Most couples $(n=64)$ were married, seven were in a stable relationship, one patient was in a new relationship, and $87.5 \%$ of the couples had children. All patients and $79.2 \%$ of the spouses provided data on their education. Half of the patients and about half of the spouses with valid data $(57.4 \%)$ reported 9 to 10 years of schooling, $47.2 \%$ of patients and $37.7 \%$ of the spouses reported 12 to 13 years of schooling, and the remainder did not specify their years of schooling. More than half of the patients $(60.9 \%)$ were retired.

Patients underwent laparoscopic radical prostatectomy; $n=31$ patients received nerve-sparing surgery to improve postoperative prospects of erectile functioning. Three patients experienced complications post-surgery, including gastrointestinal, pneumonal, or cardiovascular complications. For four patients, data on post-operative complications were not available.

\section{Measures}

Patients' reports of received spousal support were measured with an abbreviated version of the received spousal support scale from the Berlin Social Support Scales (BSSS; Schulz \& Schwarzer, 2003). Patients reported on the support received during the past week. The four items were rated on 4-point Likert-type scales ranging from does not apply at all to applies exactly. Item examples included: "My partner assured me that I can rely completely on her" and "My partner took care of things I could not manage on my own." Cronbach's alphas were $\alpha=.57(\mathrm{tl})$ and $\alpha=.71$ (t2). All means and standard deviations of measures included in this study are displayed in Table 1.

Patients' mobilized social support was measured with four adapted items of the German version of the Brief COPE (Carver, 1997; Knoll, Rieckmann, \& Schwarzer, 2005). Item examples include: "I've asked my partner for help and advice"; "I've asked my partner for comfort and understanding." Items were rated on the same 4-point Likert-type scales as in receipt of support. Cronbach's alphas were $\alpha$ $=.88(\mathrm{t} 1)$ and $\alpha=.91(\mathrm{t} 2)$.

Self-efficacy was measured by means of the General Self-Efficacy Scale (Schwarzer \& Jerusalem, 1995). Ten items refer to perceived ability to overcome barriers and cope with adversities. Responses were indicated on a 4-point scale ranging from definitely not true to exactly

TABLE 1

Pearson correlations, means, and standard deviations of the central variables

\begin{tabular}{|c|c|c|c|c|c|c|c|c|c|c|c|c|c|c|c|c|}
\hline & & $I$ & 2 & 3 & 4 & 5 & 6 & 7 & 8 & 9 & 10 & 11 & 12 & 13 & $M$ & $S D$ \\
\hline 1 & P-bother incontinence $t 2$ & 1 & & & & & & & & & & & & & 3.42 & 2.70 \\
\hline 2 & P-sexual satisfaction $t 2$ & .03 & 1 & & & & & & & & & & & & 5.10 & 2.36 \\
\hline 3 & P-relationship quality $\mathrm{t} 2$ & -.05 & $.25^{\dagger}$ & 1 & & & & & & & & & & & 4.78 & 0.95 \\
\hline 4 & P-received support $t$ & .11 & -.07 & .20 & 1 & & & & & & & & & & 2.49 & 0.52 \\
\hline 5 & P-received support $t 2$ & .11 & $.25^{\dagger}$ & .42 & .40 & 1 & & & & & & & & & 2.21 & 0.66 \\
\hline 6 & P-mobilized support tI & .19 & -.10 & .10 & .62 & .20 & 1 & & & & & & & & 1.72 & 0.91 \\
\hline 7 & P-mobilized support $t 2$ & .29 & -.02 & .08 & .35 & .42 & .59 & 1 & & & & & & & 1.30 & 0.91 \\
\hline 8 & P-self-efficacy $t 1$ & -.11 & .09 & .44 & $.24^{\dagger}$ & .27 & .07 & -.02 & 1 & & & & & & 2.26 & 0.46 \\
\hline 9 & P-self-efficacy $t 2$ & -.32 & .27 & .59 & .07 & .30 & -.10 & -.21 & .62 & 1 & & & & & 2.20 & 0.54 \\
\hline 10 & S-self-efficacy $t l$ & -.06 & -.00 & .03 & .12 & .03 & $.24^{\dagger}$ & .01 & .04 & -.02 & 1 & & & & 2.20 & 0.55 \\
\hline 11 & S-self-efficacy t 2 & -.07 & -.20 & .19 & .16 & -.05 & .40 & .20 & -.10 & .03 & .54 & 1 & & & 2.20 & 0.46 \\
\hline 12 & P-age & -.08 & .08 & .11 & .10 & .11 & -.01 & .10 & -.11 & -.01 & .12 & .09 & 1 & & 61.15 & 6.03 \\
\hline 13 & S-age & .01 & $.26^{\dagger}$ & .22 & .21 & .12 & .16 & .10 & .12 & .17 & .07 & -.03 & .70 & 1 & 58.12 & 7.49 \\
\hline
\end{tabular}

$N=72$ couples. P: patient. S: spouse. T1: pre-surgery. T2: 12 months post-surgery. All $r \geqslant .27$ are significant at $p<.05,{ }^{\dagger} p<.10$. 
true. Measures were internally consistent with $\alpha=$ $.90(\mathrm{t} 1)$ and $\alpha=.94(\mathrm{t} 2)$ for patients and $\alpha=.93$ (t1) and $\alpha=.92$ (t2) for spouses.

Patients' bother by incontinence was measured at $\mathrm{t} 2$ by one item from the International Consultation on Incontinence Questionnaire Short-Form (ICIQ-SF; International Consultation on Incontinence, 2002): "Overall, how much does leaking urine interfere with your life?' Patients were instructed to refer to the past week and responded to this item on an 11-point scale ranging from not at all to a great deal.

Patients' overall sexual satisfaction was assessed once at $t 2$ using the respective two-item subscale of the International Index of Erectile Function (IIEF; Rosen et al., 1997). Items were summed, 5-point response scales ranged from very dissatisfied to very satisfied. Cronbach's alpha was $\alpha=.82$. Patients who received nerve-sparing surgery reported a higher degree of sexual satisfaction, $t\left(\mathrm{Mr}^{460}\right)=-2.9, p<.05$; however, nerve-sparing surgery was not associated with this study's outcome variables and thus not further analysed.

Patients' relationship quality was assessed at $\mathrm{t} 2$ by one item from the Relationship Questionnaire (Hahlweg, 1979): "How happy would you rate your relationship right now?" with responses ranging between very unhappy (1) and very happy (6).

\section{Analyses}

Analyses were conducted using AMOS 6.00 (Arbuckle, 2005). To account for nonindependence in patients' and spouses' data, analyses were conducted on the dyad level and patients' and spouses' outcomes were allowed to covary in all models. Both patients' and partners' self-efficacy beliefs at 12 months post-surgery served as outcomes. Model 1 was cross-sectional. In Model 2 pre-surgery indicators of patients' received and mobilized support were tested as predictors and pre-surgery indicators of patients' and spouses' self-efficacy beliefs were included as covariates, among others. Models were computed for all 10 imputed data sets and findings were subsequently integrated using NORM's scalar estimands function (cf. Rubin, 1987; Schafer, 1999).

\section{RESULTS}

\section{Descriptives and correlations: Self-efficacy and support}

Neither patients' nor spouses' mean levels of general self-efficacy changed throughout the first year post-surgery. However, retest stabilities were only medium in size, with $r=.62$ for patients and $r$ $=.54$ for spouses. Also, patients' and spouses' selfefficacy beliefs were uncorrelated. One-year retest stabilities for patients' support indicators were $r=$ .40 for patients' received support and $r=.59$ for patients' mobilization of support (see Table 1).

Correlations further indicated marginally significant and significant cross-sectional positive relationships among patient self-efficacy and patient received spousal support at $t 1, r=.24(p<.10)$, as well as at $t 2, r=.30(p<.05)$. Furthermore, patients' self-efficacy at $\mathrm{tl}$ was positively correlated with patient-reported received support 12 months later, $r$ $=.27(p<.05)$, while patient received support at $t 1$ was uncorrelated with patient self-efficacy at $\mathrm{t} 2$. Tentative predominance of predictive directions among variables was tested with cross-lagged panel correlations using a method proposed by Kenny (e.g., 1973). However, with the synchronous correlations being equal $(z=-0.46, p=.65$ ), crosslagged coefficients among patient-reported received support and self-efficacy did not differ significantly from one another $(z=1.44, p=.15)$.

On a bivariate level, patients' mobilization of support was not correlated with patients' selfefficacy. Therefore, cross-lagged correlations involving both patient mobilized support and agency beliefs were not tested. However, patientreported mobilization of support revealed positive associations with spouses' self-efficacy beliefs. On this bivariate level, patients' $t 1$ mobilization of support only tended to be associated with higher levels of spousal self-efficacy at $\mathrm{t} 1(r=.24, p<.10)$, but yielded a positive correlation with spouses' self-efficacy 1 year later $(r=.40, p<.05)$. The association between spousal self-efficacy at $t \mathrm{I}$ and patient mobilized support at $\mathrm{t} 2$ was $r=.01(\mathrm{~ns})$. At equal synchronous correlations $(z=.30, p=.76)$, cross-lagged correlations among patients' mobilized support and spouses' self-efficacy differed significantly $(z=-3.05, p=.002$ ).

All presumed $t 2$ covariates, i.e., patient-reported bother by incontinence, sexual satisfaction, and relationship quality, revealed medium to strong cross-sectional relations with patients' self-efficacy (see Table 1). As neither patients' nor spouses' ages were related with the outcomes, they were not further analysed.

\section{Models predicting self-efficacy 12 months post-surgery}

Cross-sectional model. Simultaneous crosssectional prediction of patients' and spouses' 
self-efficacy at 12 months after prostatectomy resembled bivariate associations (see Figure 1). Higher levels of bother by incontinence were related to lower self-efficacy in patients, but unrelated to spouses' self-efficacy. Patients' accounts of relationship quality were positively related with both partners' self-efficacy beliefs. Net of covariates, patient-reported received support at 12 months post-surgery was marginally positively associated $(p<.10)$ with patients' self-efficacy, while it was unrelated to spouses' self-efficacy. Patients' mobilization of support at 12 months post-surgery was now negatively related to their own self-efficacy beliefs at the same time. Higher levels of patient-mobilized support at $\mathrm{t} 2$ predicted higher concurrent levels of spouses' agency beliefs.

Longitudinal model. Among pre-surgery support indicators, none predicted change in patient selfefficacy over 1 year. Patient-reported support mobilization at $t l$ was positively associated with changes in spouses' self-efficacy (see Figure 2). Positive effects of $t 2$ patient-reported relationship satisfaction with both partners' residualized selfefficacy remained strong. Also, with pre-surgery spousal self-efficacy controlled, patient-reported sexual satisfaction at $t 2$ was now significantly negatively associated with spouses' self-efficacy at $\mathbf{t} 2$.

\section{DISCUSSION}

\section{Support and self-efficacy}

This study tested patient mobilized and received support as predictors of self-efficacy in prostatectomy patients and their partners within 1 year postsurgery. In accord with the enabling hypothesis of support, we explored whether support constructs would act to bolster up self-efficacy.

Patients' received support at both measurements was associated with higher concurrent levels of general self-efficacy. Nevertheless, aside from being cross-sectional, associations were weak, mostly marginally significant $(p<.10)$ and, as shown by Figure 1, partly accounted for by rival predictors such as concurrent patient-reported

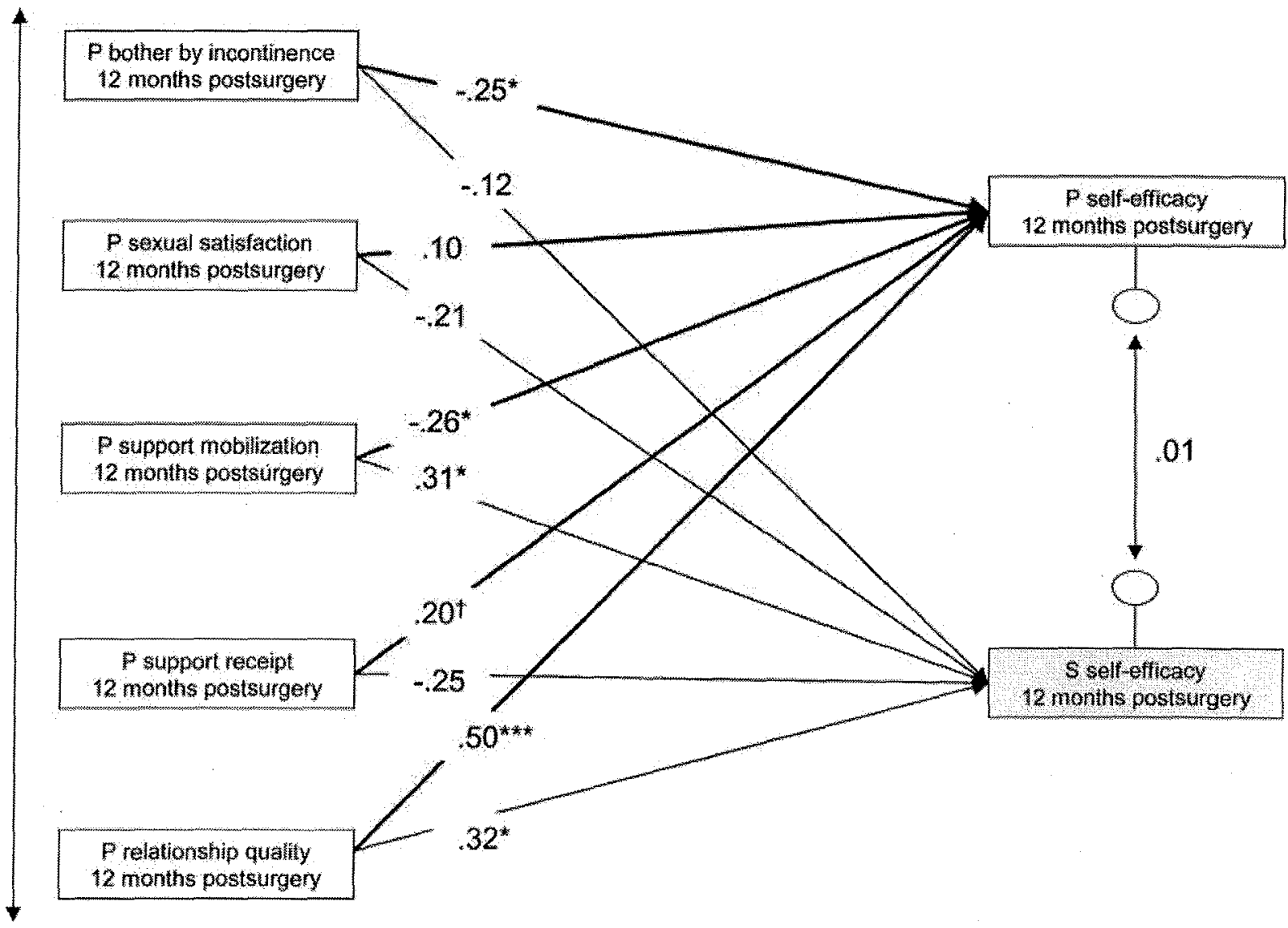

Figure 1. Cross-sectional path model predicting patients' and spouses' self-efficacy beliefs at 1 year post-surgery $(N=$ 72 couples). ${ }^{\dagger} p<.10 ;{ }^{*} p<.05 ;{ }^{* * *} p<.001$. 


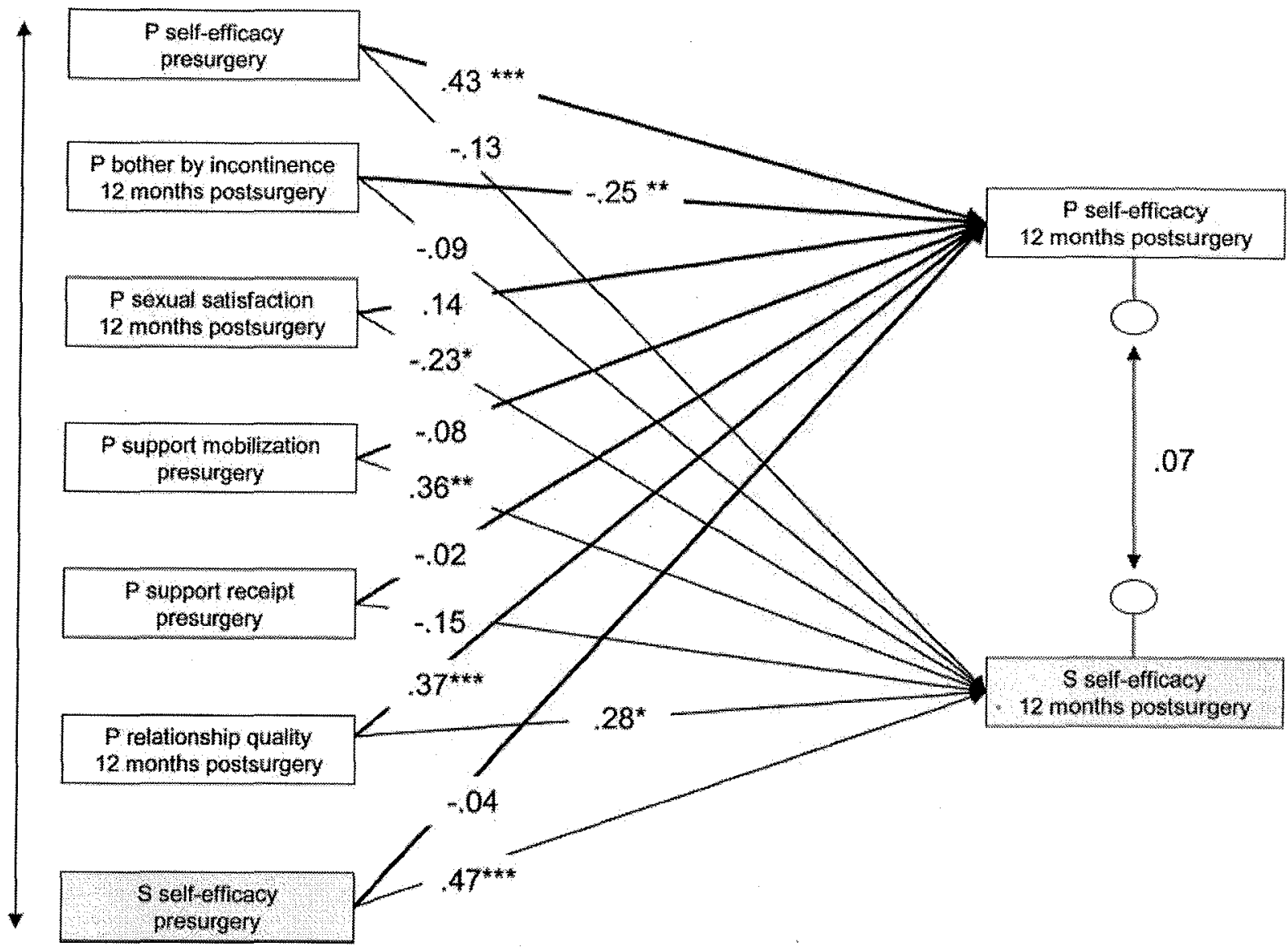

Figure 2. Path model predicting patients' and spouses' changes in self-efficacy beliefs from pre-surgery to 1 year postsurgery $\left(N=72\right.$ couples). ${ }^{*} p<.05 ; * * p<.01,{ }^{* * *} p<.001$.

relationship satisfaction. One explanation for the lack of longitudinal findings could concern the measurement interval. As was hypothesized for direct effects of received support on recipients' well-being (Gleason, lida, Bolger, \& Shrout, 2003), enabling functions of received support may also be short lived. Schröder et al. (1998), for instance, investigated associations between levels of received support and self-efficacy in patients within a 1week interval. Moreover, although fairly strong and theoretically meaningful bivariate associations of patients' received support with other variables (e.g., mobilization of support) lent credence to the measure, low homogeneity in the pre-surgery assessment of received support could have prevented significant longitudinal effects.

Concerning patient mobilization of support, a cross-sectional negative partial association emerged, indicating that more mobilization, net of concurrent receipt or relationship satisfaction, was associated with lower concurrent levels of patientreported self-efficacy. However, the predictive direction of this finding remains unclear: Less efficacious patients may mobilize more support.
On the other hand, mobilization of support might also reduce rather than increase a mobilizer's agency beliefs. Contrary to more agentic assumptions of mobilization as a goal-oriented utilization of external resources, for the person who mobilizes, asking for help might represent a signal of defeat. In this sense, mobilization could serve as a reminder of being unable to deal with stressful circumstances alone and consequently reduce self-efficacy (e.g., Aldwin \& Yancura, 2004).

Furthermore, we assumed that patients' support mobilization would enhance partners' self-efficacy. We proposed that being asked for help could serve as an indirect symbolic experience in which the future providers receive feedback about their competency as it is perceived by the person in need. Additionally, being mobilized usually leads to support provision, which in turn can be associated with further mastery experiences. As both the 1-year longitudinal and the cross-sectional model indicated independent predictions of patient mobilized support on level and change of spouses' self-efficacy, data generally supported these assumptions. 


\section{Post-operative morbidities and relationship quality as predictors of self-efficacy}

Patients' bother by incontinence at 12 months post-surgery was related to lower self-efficacy, even while controlling for pre-surgery levels of the same. If urinary incontinence restricts functional ability and autonomy, it should also frustrate successful coping with everyday chores. As a consequence, mastery experiences should become less likely, which again should feed back to patients' agency beliefs. Patients' overall sexual satisfaction at 1 year post-surgery, however, did not account for variance in same-time patient selfefficacy once rival predictors, such as relationship satisfaction, were controlled. At this point, patients might have begun to try alternate forms of intimacy with their partners or redefined goals in sexual performance. The possibility that patients might have disconnected their sexual satisfaction from general agency beliefs (Eton et al., 2001), as well as the rather inconsistent effect of higher patient-reported sexual satisfaction predicting a decrease in spousal self-efficacy, both await replication. Further clarification of these results should be achieved by using more domainspecific indicators of self-efficacy beliefs (regarding sexuality; Eton et al., 2001).

Patients' concurrent relationship satisfaction was a strong predictor of patients' and spouses' self-efficacy 12 months after surgery. Coyne and Smith (1994) characterize relationship adjustment and how patients' and spouses' actions fit together as crucial determinants of the recovery processes. The process of adjusting to post-operative morbidities following prostatectomy requires changes in daily routines and couples' lifestyles (Gray et al., 2000). Good marital adjustment in light of post-operative consequences may represent a proxy for the orchestration of the couples' efforts to adapt to the situation.

\section{Limitations and outlook}

In the present study, significance levels were not adjusted for multiple testing and associations at $10 \%$ significance levels were discussed. As findings at $10 \%$ significance levels are not uniformly accepted, we would like to highlight this limitation. Additionally, the sample size was small, which may result in power problems. The reported findings should thus be treated with care pending future replication (Cohen, 1994).

As evidence on enabling functions of received support reported by patients was cross-sectional and inconclusive, it resembled findings reported by the literature on potential distress-lowering functions of support. In these, received support often fails to lower distress in the recipient and is instead counterproductive. Receiving help is generally associated with costs (e.g., damage to self-esteem) and benefits (i.e., receiving needed aid), and the balance of both is moderated by many factors. Suggested moderators of effective received support that were not addressed in the present study include relationship characteristics (e.g., reciprocity; Gleason et al., 2003), recipient characteristics (e.g., degree of need for support; Burkert, Knoll, \& Gralla, 2006), or provider characteristics (e.g., appraisal detection bias; Knoll, Schulz, Schwarzer, \& Rosemeier, 2006). Future research should test the role of such moderators in the longitudinal received support-self-efficacy relationship.

Regarding mobilization of support as a predictor, evidence concerning patients' self-efficacy was inconclusive. However, a strong longitudinal enabling effect emerged in spouses who were asked for help by their convalescent partners. Coming studies should confirm this relationship and test whether mobilization during nonstressful circumstances has a similar effect on the intended providers' agency beliefs.

\section{REFERENCES}

Aldwin, C. M., \& Yancura, L. A. (2004). Coping and health: A comparison of the stress and trauma literatures. In P. P. Schnurr \& B. L. Green (Eds.), Trauma and health: Physical health consequences of exposure to extreme stress (pp.99-125). Washington, DC: American Psychological Association.

Anehensel, C. S., Pearlin, L. I., Mullan, J. T., Zarit, S. H., \& Whitlatch, C. J. (1995). Profiles in caregiving: The unexpected career. San Diego, CA: Academic Press.

Arbuckle, J. L. (2005). Amos 6.0 Update to the Amos User's Guide. Chicago: SmallWaters.

Bandura, A. (1997). Self-efficacy: The exercise of control. New York: Freeman.

Benight, C., \& Bandura, A. (2004). Social cognitive theory of posttraumatic recovery: The role of perceived self-efficacy. Behaviour Research and Therapy, 42, 1129-1148.

Broome, B. A. S. (2003). The impact of urinary incontinence on self-efficacy and quality of life Health and Quality of Life Outcomes, 35, Article 1. Retrieved November 22, 2006, from http:// www.hqlo.com/content/1/1/35.

Bullinger, M., \& Kirchberger, J. (1998). Der SF-12. [The SF-12.] In M. Bullinger \& J. Kirchberger (Eds.), 
Der SF-36-Fragebogen zum Gesundheitszustand (S 65-72). Göttingen, Germany: Hogrefe Verlag.

Burkert, S., Knoll, N., \& Gralla, O. (2006). Social support and stress in prostatectomy patients and their spouses. In P. Buchwald (Ed.), Stress and anxiety-Application to health, community, work place, and education (pp.36-41). Cambridge, UK: Cambridge Scholar Press.

Carver, C. S. (1997). You want to measure coping but your protocol's too long: Consider the Brief COPE. International Joumal of Behavioral Medicine, 4, 92-100.

Cheung, S., \& Sun, S. Y. K. (2000). Effects of selfefficacy and social support on the mental health conditions of mutual-aid organization memebers. Social Behavior and Personality, 28, 413-422.

Cohen, J. (1994). The earth is round $(\mathrm{p}<.05)$. American Psychologist, 49, 997-1003.

Coyne, J. C., \& Smith, D. A. F. (1994). Couples coping with myocardial infarction: Contextual perspective on patient self-efficacy. Journal of Personality and Social Psychology, 8, 1-13.

Duncan, T. E., \& McAuley, E. (1993). Social support and efficacy cognitions in exercise adherence: A latent growth curve analysis. Journal of Behavioral Medicine, 16, 199-218.

Eton, D. T., \& Lepore, S. J. (2002). Prostate cancer and health-related quality of life: A review of the literature. Psycho-Oncology, 11, 307-326.

Eton, D. T., Lepore, S. J., \& Helgeson, V. S. (2001). Early quality of life in patients with localized prostate carcinoma. An examination of treatment-related, demographic, and psychosocial factors. Cancer, 92, $1451-1459$.

European Association of Urology. (2005). Guidelines on prostate cancer. Retrieved November 22, 2006, from http://www.uroweb.org/nc/professional-resources/ guidelines/online

Gleason, M. E. J., Iida, M., Bolger, N., \& Shrout, P. E. (2003). Daily supportive equity in close relationships. Personality and Social Psychology Bulletin, 29, 1036-1045.

Gray, R. E., Fitch, M., Phillips, C., Labreque, M., \& Fergus, K. (2000). Managing the impact of illness: The experiences of men with prostate cancer and their spouses. Journal of Health Psychology, 5, 531-548.

Hahlweg, K. (1979). Konstruktion und Validierung des Partnerschaftsfragebogens PFB [Construction and validation of the relationship questionnaire PFB]. Zeitschrift für Klinische Psychologie, 8, 17-40.

Heckhausen, J., \& Schulz, R. (1993). Optimisation by selection and compensation: Balancing primary and secondary control in life-span development. International Journal of Behavioral Development, 16, $287-303$.

International Consultation on Incontinence (ICI). (2002). ICIQ-SF. International Urogynecological Journal, 13, 57-58.
Kenny, D. A. (1973). Cross-lagged and synchronous common factors in panel data. In A. S. Goldberger \& O. D. Duncan (Eds.), Structual equations in social sciences. New York: Seminar Press.

Knoll, N., Rieckmann, N., \& Schwarzer, R. (2005). Coping as a mediator between personality and stress outcomes: A longitudinal study with cataract surgery patients. European Journal of Personality, 19 , 229-247.

Knoll, N., Schulz, U., Schwarzer, R., \& Rosemeier, H. P. (2006). Provider's appraisal detection bias and the efficacy of received support in medical students preparing for an exam. British Journal of Social Psychology, 45, 599-615.

Luszczynska, A., Sarkar, Y., \& Knoll, N. (2007). Predictors of adherence to highly active antiretroviral therapy. Patient Education and Counseling, 66, 37-42.

Rosen, R. C., Riley, A., Wagner, G., Osterloh, I. H., Kirkpatrick, J., \& Mishra, A. (1997). The International Index of Erectile Function (IIEF): A multidimensional scale for assessment of erectile dysfunction. Urology, 49, 822-830.

Rubin, D. B. (1987). Multiple imputation for nonresponse in surveys. New York: John Wiley \& Sons.

Saltzman, K. M., \& Holahan, C. J. (2002). Social support, self-efficacy, and depressive symptoms: An integrative model. Journal of Social and Clinical Psychology, 21, 309-322.

Schafer, J. L. (1999). NORM: Multiple imputation of incomplete multivariate data under a normal model, version 2. Software for Windows 95/98/NT. Retrieved January 2, 2003, from http://www.stat.psu.edu/ jls/ misof twa.html.

Schröder, K. E., Schwarzer, R., \& Konertz, W. (1998). Coping as a mediator in recovery from heart surgery: A longitudinal study. Psychology \& Health, 13, 83-97.

Schulz, U., \& Schwarzer, R. (2003). Soziale Unterstützung bei der Krankheitsbewältigung: Die Berliner Social Support Skalen (BSSS) [Social support and coping with illness: The Berlin Social Support Scales (BSSS)]. Diagnostica, 49, 73-82.

Schwarzer, R. (Ed.) (1992). Self-efficacy: Thought control of action. Washington, DC: Hemisphere.

Schwarzer, R., \& Jerusalem, M. (1995). Generalized selfefficacy scale. In J. Weinman, S. Wright, \& $\mathrm{M}$. Johnston (Eds.), Measures in health psychology: $A$ user's portfolio. Causal and control beliefs (pp. 35-37). Windsor, UK: NFER-NELSON.

Schwarzer, R., \& Knoll, N. (2007). Functional roles of social support within the stress and coping process: A theoretical and empirical overview. International Journal of Psychology, 42, 243-252.

Shindel, A., Quayle, S., Yan, Y., Husain, A., \& Naughton, C. (2005). Sexual dysfunction in female partners of men who have undergone radical prostatectomy correlates with sexual dysfunction of the male partner. Journal of Sexual Medicine, 2, 833-841. 